Jurnal SPORTIF: Jurnal Penelitian Pembelajaran

Vol. 6 No. 2, Agustus 2020, pp. 449-465

doi) https://doi.org/10.29407/js_unpgri.v6i2.14564

\title{
Kontribusi motor educability terhadap kemampuan senam ritmik alat simpai pada siswa sekolah dasar
}

\section{The contribution of motor educability on the elementary school student's ability in rhythmic gymnastics using sport hoop}

\author{
Sahabuddin ${ }^{1}$, Hikmad Hakim ${ }^{2}$, dan Syahruddin ${ }^{3}$
}

1,2,3Faculty of Sports Science, Universitas Negeri Makassar, Street of Wijaya Kusuma Raya No. 14, Makassar City, South Sulawesi Province, 90222, Indonesia

Received: 13 July 2020; Revised: 1 August 2020; Accepted: 21 August 2020

\begin{abstract}
Abstrak
Penelitian ini bertujuan untuk mengetahui hasil kontribusi motor educability terhadap kemampuan senam ritmik alat simpai pada siswa sekolah dasar. Penelitian ini adalah metode deskriptif korelatif. Populasinya adalah siswa SD seKota Makassar dengan sampel dari 14 kecamatan diambil tiap sekolah sebagai perwakilan kecamatan sebanyak 10 orang siswa putri, secara keseluruhan sampel berjumlah 140 orang siswa putri dengan teknik cluster random sampling. Instrumen yang digunakan adalah tes dengan 8 item tes pemanduan bakat senam dan senam ritmik simpai menggunakan panduan instrumen tes Federation Internasional de Gymnastique (FIG). Teknik analisis data yang digunakan adalah statistik korelasi dan regresi pada taraf signifikan $5 \%$. Berdasarkan hasil pengujian analisis korelasi dan regresi data motor educability terhadap kemampuan senam ritmik alat simpai pada siswa SD se-Kota Makassar diperoleh nilai regresi (Ro) 0,222 dengan tingkat probabilitas $(0,000)<\alpha 0,05$, untuk nilai $\mathrm{R}$ Square (koefesien determinasi) 0,049. Maka motor educability benar-benar berpengaruh secara signifikan terhadap kemampuan senam ritmik alat simpai. Pada penelitian ini terbatas pada alat simpai, diharapkan dalam penelitian kedepan senam ritmik menggunakan alat-alat yang lain.
\end{abstract}

Kata kunci: motor educability, senam ritmik, alat simpai.

\begin{abstract}
This study aims to determine the contribution of motor educability on the ability of students' rhythmic gymnastics using sport hoop. This research uses descriptive correlative method. The population is elementary school students in Makassar with sample taken from 10 sub-districts in which 10 female students become each sub-district representatives. Hence, the sample consists of 140 female students selected with cluster random sampling technique. The instruments used are 8 item test of gymnastics talent scouting and hoop rhythmic gymnastics using federation internasional de Gymnastique (FIG) test instrument guide. The data analysis technique used is statistical correlation and regression at a significant level of 5\%. Based on the results of the correlation analysis and motor educability data regression testing on the rhythmic gymnastics ability with sport hoop in elementary school students in Makassar, the regression value (Ro) is 0.222 with a probability level $(0.000)<0.05$, for the value of $R$ Square (coefficient of determination) 0.049 . It can be concluded that motor educability really has a significant effect on the ability of rhythmic gymnastics using sports hoop. This research object is limited in analyzing sport hoop, so further research on rhythmic
\end{abstract}

Correspondence author: Sahabuddin, Universitas Negeri Makassar, Indonesia.

Email: sahabuddin@unm.ac.id 
gymnastics may apply other sport media.

Keywords: motor educability, rhythmic gymnastics, sport hoop.

\section{PENDAHULUAN}

Kondisi maupun kemampuan siswa sangat berbeda-beda ditinjau dari kemampuan adaptasi siswa terhadap proses pembelajaran, situasi tersebut sering dihadapi seorang guru dalam proses pembelajaran (Atiyah, Wahidin, \& Roviati, 2016). Menurut Cahyono (2015) usia dini bagi anak adalah salah satu faktor penentu proses tumbuh kembang dalam proses kehidupannya. Oleh karena itu, motivasi bagi anak usia dini sangat diperlukan agar anak dapat berkembangan secara baik (Adji, 2017; dan Makulua, 2018). Dalam pembelajaran penting bagi guru untuk mengetahui kemampuan persepsi gerak setiap siswa, mengingat kemampuan siswa berbeda-beda dalam proses pembelajaran siswa dapat menerima kompetensi keterampilan gerak yang diajarkan (Mahardhika, 2016).

Usia anak ditinjau secara biologis belum bisa menjamin keterampilan gerak bagi anak, namun usia anak tinjauan secara kronologis dapat mempengaruhi terhadap keterampilan gerak dan faktor keterampilan anak juga terletak pada kemampuan mempresepsikan gerak yang diajarkan (Aulia, 2015). Selain itu, proses latihan yang telah ditempuh sangat menentukan terhadap penguasaan materi dengan baik (Murwaningsih, 2018; dan Nugraha \& Fuad, 2019). Apabila anak usia sekolah dasar sudah memiliki karakteristik perkembangan dan pertumbuhan yang baik, maka anak usia sekolah dasar akan diprediksi mampu mengontrol serta menjaga keseimbangan tubuhnya (Azizah \& Richval, 2018).

Senam merupakan bentuk gerakan yang menggabungkan bagian tubuh beserta komponen fisik dengan irama yang terpadu (Ristanti, Setiawan, \& Setiawan, 2019). Gerakan dalam olahraga senam dapat digunakan pada olahraga secara keseluruhan serta olahraga senam itu sendiri (Setiawan, 2018; dan Juntara, 2019). Senam ritmik adalah gerakan senam yang dilakukan dengan irama musik atau latihan bebas 
yang dilakukan secara berirama, senam ritmik sangat erat hubungannya dengan konsentrasi (Sari et al., 2017).

Banyak pembelajaran yang tersedia disekolah bagi peserta didik untuk meningkatkan kemampuan gerak diantaranya pembelajaran senam. Lavin (2008) berpendapat bahwa manfaat senam diantaranya: (1) meningkatkan agility, mengubah tingkat atau arah memutar badan, gerakan berbalik badan atau berjalan dengan menggunakan tubuh lainnya; (2) meningkatkan keseimbangan, dalam beberapa gerakan senam dibutuhkan sebuah posisi simertis dan asimetris yang baik; (3) meningkatkan koordinasi, dalam senam koordinasi dapat ditingkatkan melalui berjalan tidak menggunakan kaki tetapi menggunakan bagian tubuh yang lain di sekitar tubuh dan ruang. Oleh sebab itu pembelajaran senam sangat baik jika digunakan untuk meningkatkan kemampuan gerak bagi peserta didik. Selain itu dalam kegiatan senam peserta didik akan mendapatkan gerak yang harmonis akibat dari gerakan senam yang dipelajari.

Senam ritmik dijadikan sebagai olahraga yang indah denga menggabungkan berbagai elemen antara senam, balet, dan tari serta manipulasi gerakan antara alat dan ekspresi diri dengan iringan musik. Koreografi yang indah harus ditampilkan menggunakan alat berupa pita, bola, tali, gada, dan simpai dengan berbagai elemen gerakan lompatan, keseimbangan, dan putaran senam ritmik termasuk dalam golongan senam yang menggunakan irama (Herlambang, 2017).

Beberapa studi menjelaskan faktor performa senam ritmik melalui perspektif keseluruhan dimana saling terkait antara latihan dan performa (Utami, Kartika, Damayanti, \& Nugroho, 2004; Di Cagno et al. 2018; Fernández-Villarino et al. 2018), dan penelitian lain menjelaskan beberapa faktor prediksi seperti karakteristik antopometri, kondisi fisik atau aspek teknis dari performa secara terpisah (Miletić, Katić, \& Males, 2004).

Model senam ritmik yang diterapkan pada siswa SD diharapkan dapat meningkatkan aktivitas pola-pola gerak anak. (Hanief \& Sugito, 
2015, dan Baharun, 2016) menyatakan bahwa agar mendapatkan pengalaman gerak yang baik pada anak-anak maka dalam mendidik anak usia dini harus memperhatikan pembelajaran gerak. Hughes (2009) menyatakan komponen yang sangat esensial untuk pemahaman tentang pengetahuan atau kognitif adalah aktivitas fisik. Gerak anak secara alamiah serta sensor merupakan konsep pola gerak pada anak (Primasoni 2014; Rahmadani, 2014; dan Sujiono, Sumantri, \& Chandrawati, 2014). Untuk mengotimalkan kemampuan gerak kasar dan lokomotor siswa dibutuhkan sebuah perencanaan kegiatan aktivitas jasmani (Aryamanesh \& Sayyah, 2014).

Media berarti perantara yaitu perantara sumber pesan dengan penerima pesan (Zaman, Hernawan, \& Eliyawati, 2005). Media yang digunakan adalah simpai yang merupakan alat yang bentuknya menyerupai cincin atau lingkaran yang bahannya terbuat dari fiber glass atau bisa juga terbuat dari sebilah bambu atau rotan yang dibuat melingkar menghubungkan ujung-perujung. Simpai ini diperindah dengan diberi warna atau corak yang menarik berasal dari cat, selotif, atau kertas warna yang di lekatkan sebagai hiasan melingkar pada simpai memiliki tujuan untuk menambah keindahan dan motifnya.

Permainan simpai ini memiliki gerakan-gerakan senam ritmik pada gerakannya dapat mengembangkan komponen biomotor pada anak-anak yang memainkannya, diantaranya terdapat biomotor kekuatan, kecepatan reaksi, koordinasi dan kelentukan pada ekstremitas atas yakni pada lengan. Hal ini sejalan dengan pendapat yang disampaikan oleh (Nugraha, Zulela, \& Fuad, 2019) bahwa simpai sebagai media penting dalam mengembangkan keterampilan senam ritmik anak yang memberikan sumbangan berarti bagi perkembangan keterampilan anak.

Kajian penelitian yang dilakukan Mahardhika (2016) menunjukkan terdapat suatu hubungan antara metode pembelajaran latihan dengan motor educability terhadap keterampilan teknik dalam olahraga bola basket. Penelitian yang dilakukan Bardid et al. (2017) menyatakan bahwa jenis kelamin laki-laki dan perempuan mempengaruhi perkembangan 
motorik, hal ini dapat terjadi karena anak-anak yang berjenis kelamin lakilaki akan cepat menguasai gerakan yang berjenis keterampilan kontrol, dibanding anak perempuan yang cenderung cepat menguasai keterampilan lokomotor. Kajian penelitian yang dilakukan Houwen, Visser, van der Putten, \& Vlaskamp (2016) terkait motorik, kognitif, dan bahasa berkaitan dengan perkembangan motorik halus dan kasar yang berhubungan dengan kognisi anak. Penelitian Sari \& Karmila (2015) menunjukkan bahwa untuk dapat peningkatan stimulus anak berkaitan dengan kognitif dan motorik kasar anak. Tujuan penelitian ini adalah untuk mengetahui kontribusi motor educability dengan menggunakan keterampilan fisik atau dengan olahraga terhadap senam ritmik dengan menggunakan simpai. Kontribusi motor educability terhadap senam ritmik dalam penelitian ini dengan menggunakan pendekatan pendidikan jasmani sangat cocok untuk siswa sekolah dasar, karena motor educability merupakan dasar dalam gerak setiap individu dalam aktivitas keseharian, akan tetapi dalam pengembangan kemampuan atau keterampilan suatu cabang olahraga adalah dasar untuk menjadi sebuah gerak yang terarah, seperti pada cabang olahraga senam di nomor senam ritmik seperti yang dikatakan Lesmana (2018) bahwa dengan pendidikan jasmani merupakan suatu media dalam mendorong perkembangan motorik, kemampuan fisik pengetahuan dan penalaran, penghayatan nilai-nilai (sikap, mental, emosional, spiritual, dan sosial), serta pembiasaan pola hidup sehat yang betujuan untuk merangsang pertumbuhan dan perkembangan secara seimbang.

Studi ini berupaya mengetahui kontribusi motor educability terhadap senam ritmik dengan menggunakan alat simpai. Beberapa penelitian tentang kontribusi motor educability menyimpulkan bahwa dengan keterampilan fisik atau dengan olahraga dapat digunakan untuk meningkatkan motor educability paada siswa sekolah dasar. Pemahaman motor educability sebagai bagian dari proses pembelajaran sangatlah penting, hal ini karena pembelajaran merupakan wadah yang sangat tepat untuk sisiwa yang ingin mengembangkan potensi, khususnya dalam 
bidang olahraga (Lesmana, 2018). Selain itu menurut Haqiyah \& Riyadi (2018) motor educability yang dimiliki siswa akan menjadikan lebih mudah untuk belajar gerakan baru dan mengembangkan kemampuannya terhadap bidang olahraga. Masalah dan tujuan dalam penelitian ini mengenai kontribusi dan implikasi terhadap senam ritmik. Urgensi penelitian ini hasilnya dapat direkomendasikan sebagai acuan dalam pembelajaran olahraga bahwa motor educability berpengaruh dalam senam ritmik.

\section{METODE}

Metode penelitian yang digunakan dalam penelitian adalah metode deskriptif korelatif. Populasi dalam penelitian ini adalah seluruh siswa SD Negeri se-Kota Makassar. Sampel yang digunakan adalah siswa putri SD Negeri se-Kota Makassar dengan jumlah 140 orang yang terdiri dari 10 orang dari sekolah diwakil tiap kecamatan dengan menggunakan teknik cluster sampling.

Tabel 1. Jumlah Sampel dalam Setiap Sekolah Perkecamatan

\begin{tabular}{|c|c|c|c|}
\hline No. & Nama Sekolah & Kecamatan & Jumlah \\
\hline 1. & SDN Pajjaiang 2 & Biringkanaya & 10 orang \\
\hline 2. & SDN Kampus UNHAS I & Tamalanrea & 10 orang \\
\hline 3. & SDN Bayang & Tamalate & 10 orang \\
\hline 4. & SDN Pannara & Manggala & 10 orang \\
\hline 5. & SDN Mongosidi II & Makassar & 10 orang \\
\hline 6. & SD Inp. Tabaringan I & Ujung Tanah & 10 orang \\
\hline 7. & SDN Sudirman I & Ujung Pandang & 10 orang \\
\hline 8. & SDN Timor I & Wajo & 10 orang \\
\hline 9. & SDN Kompleks IKIP & Rappocini & 10 orang \\
\hline 10. & SDN Panaikang II & Panakukang & 10 orang \\
\hline 11. & SDN 67 Rappokalling & Tallo & 10 orang \\
\hline 12. & SD Inp. Bertingkat Mamajang II & Mamajang & 10 orang \\
\hline 13. & SD Inp. Mariso III & Mariso & 10 orang \\
\hline \multirow[t]{2}{*}{14.} & SDN Pontiku I & Bontoala & 10 orang \\
\hline & Total & & 140 orang \\
\hline
\end{tabular}

Berkaitan dengan penelitian ini ada dua instrumen yang digunakan, untuk mengetahui motor educability menggunakan istrumen tes pemanduan bakat senam sebanyak 8 item (Kemendikbud, 2004) sedangkan untuk senam ritmik simpai menggunakan panduan instrumen 
tes Federation Internasional de Gymnastique (FIG) (Gymnastique, 2009). Instrumen dapat dlihat pada tabel 2 dan tabel 3 berikut:

Tabel 2. Penilaian Motor educability untuk Pesenam Ritmik

\begin{tabular}{|c|c|c|c|c|c|}
\hline \multirow{2}{*}{ No. } & \multirow{2}{*}{ Kualitas fisik } & \multirow{2}{*}{ Jenis tes } & \multicolumn{3}{|c|}{ Skor } \\
\hline & & & 6 & 4 & 2 \\
\hline 1. & Kecepatan & Lari 20 meter, star melayang & 3,5 & $3,9-4,1$ & 4,6 \\
\hline 2. & Kekuatan dinamis & $\begin{array}{l}\text { Angkat tungkai hingga } 90^{\circ} \\
\text { selama } 30 \text { detik (posisi } \\
\text { berdiri) }\end{array}$ & 15 & 10 & 7 \\
\hline 3. & Daya ledak & 1. Vertical jump (cm) & 38 & 30 & 20 \\
\hline \multirow[t]{4}{*}{4.} & Kelentukan & 1. Membungkuk ke depan & 23 & $15-18$ & 11 \\
\hline & & 2. Split samping & 0 & 2 & 5 \\
\hline & & 3. Sikap jembatan & 0 & $15-20$ & 25 \\
\hline & & $\begin{array}{l}\text { 4. Kelentukan aktif dari } \\
\text { panggul (posisi } \\
\text { telentang) }\end{array}$ & $135^{\circ}$ & $126^{0}$ & $90^{\circ}$ \\
\hline 5. & $\begin{array}{l}\text { Keseimbangan } \\
\text { dinamis }\end{array}$ & $\begin{array}{l}\text { Jalan jingjit di atas bangku } \\
\text { (balok titian) }\end{array}$ & $\begin{array}{l}\text { Tidak } \\
\text { goyah }\end{array}$ & Goyah & $\begin{array}{l}\text { Sulit } \\
\text { maju }\end{array}$ \\
\hline 6. & Irama & Bergerak mengikuti irama & $\begin{array}{l}\text { Tepat } \\
\text { irama }\end{array}$ & $\begin{array}{c}\mathrm{Di} \\
\text { antara }\end{array}$ & $\begin{array}{l}\text { Lepas } \\
\text { irama }\end{array}$ \\
\hline 7. & Rasa gerak & $\begin{array}{l}\text { Melangkah mata terbuka } \\
\text { dan mata tertutup }\end{array}$ & $0-10$ & $11-30$ & $>30$ \\
\hline 8. & Koordinasi umum & $\begin{array}{l}\text { Lompat berputar pada poros } \\
\text { longitudinal }\end{array}$ & $360^{\circ}$ & $300^{\circ}$ & $270^{\circ}$ \\
\hline
\end{tabular}

Tabel 3. Dasar Dalam Penilaian Senam Ritmik Nomor Simpai

\begin{tabular}{|c|c|c|c|c|}
\hline $\begin{array}{l}\text { Value } \\
\text { Part/Nilai } \\
\text { Faktor } \\
\text { Kesulitan }\end{array}$ & Elemen Yang Ditawarkan & & $\begin{array}{l}\text { Starting } \\
\text { Value/ } \\
\text { Nilai Awal }\end{array}$ & $\begin{array}{l}\text { Deduction/ } \\
\text { Total Nilai } \\
\text { Keselahan } \\
\text { Umum }\end{array}$ \\
\hline 0,30 & Flexibility wave & $\sqrt{ }$ & & \\
\hline 0,30 & Spin hoop dengan step $4 \mathrm{x}$ & $\sqrt{ }$ & & \\
\hline 1,00 & $\begin{array}{l}\text { Step kiri pivot } 360^{\circ} \text { balance } 90 \text { spin hoop } \\
\text { kanan }\end{array}$ & $\sqrt{ }$ & & \\
\hline 0,30 & Sene $1 \mathrm{x}$ & $\sqrt{ }$ & SV: 8,30 & $\begin{array}{l}\text { Deduction: } \\
0.90\end{array}$ \\
\hline 0,30 & Spin hoop hand, jum ring $2 \mathrm{x}$ & $\sqrt{ }$ & & \\
\hline 0,70 & Flexibility MG kick & $\sqrt{ }$ & & \\
\hline 0,50 & $\begin{array}{l}\text { Lempar hoop sene } 1 \times \text { tangkap hoop } \\
\text { dengan kaki injak }\end{array}$ & $\sqrt{ }$ & & \\
\hline 1,70 & Balance samping + jump skrup $1 \mathrm{x}$ & $\sqrt{ }$ & & \\
\hline 0,20 & Rotasi pinggang & $\sqrt{ }$ & & \\
\hline 1,70 & $\begin{array}{l}\text { Hoop boomerang flexi pance body } 90^{\circ} \text { kaki } \\
180^{\circ} \text { - jump cossack - hoop passing - flexi } \\
\text { arab }\end{array}$ & $x$ & & \\
\hline
\end{tabular}


Sahabuddin, Hikmad Hakim, dan Syahruddin

Kontribusi motor educability terhadap kemampuan senam ritmik alat simpai pada siswa sekolah dasar

Lanjutan Tabel 3. Dasar dalam Penilaian Senam Ritmik Nomor Simpai

\begin{tabular}{clll}
\hline 1,50 & $\begin{array}{l}\text { Skipping samping 1/2 putaran 3 } \\
\mathrm{x}\end{array}$ & $\sqrt{ }$ & \\
0,75 & $\begin{array}{l}2 \times \text { jump ring hop ditangkap, } \\
\text { pivot } 720^{\circ}\end{array}$ & $\sqrt{ }$ & \\
0,75 & $\begin{array}{l}\text { Lempar oblig roll depan } \\
\text { tangkap hop dengan kaki }\end{array}$ & $\sqrt{ }$ & \\
Total VP. 10.00 & & SV & Final Score \\
& & & 7,40 \\
\hline
\end{tabular}

Tabel 4. Gerakan yang Dilakukan Deduction/Pemotongan

\begin{tabular}{cll}
\hline No. & \multicolumn{1}{c}{ Gerakan } & \multicolumn{1}{c}{ Deduction/Pemotongan } \\
\hline 1 & Pivot $360^{\circ}$ & $-0,1$ kurang derajat putaran $15^{\circ}$ \\
2 & Balance $90^{\circ}$ & $-0,1$ kurang derajat posisi pada saat menahan \\
3 & Sene $1 \mathrm{x}$ & kaki $10^{\circ}$ \\
4 & Jump ring $2 x$ & $-0,1$ kurang lentur \\
5 & Flexi MG Kick & $-0,2$ jump kurang tinggi \& ujung kaki tidak point \\
& Obling roll depan tangkap & $-0,1$ posisi MGKick pada saat bertahan sedikit \\
& dengan kaki & $-0,3$ simpai lepas \\
\hline
\end{tabular}

Data hasil penelitian dianalisis secara statistik dengan teknik pengolahan data menggunakan program SPSS (Statistical Product and Service Solutions). Untuk gambaran mengenai motor educability dan senam ritmik nomor simpai dengan menggunakan descriptive statistic, sedangkan untuk memperoleh hasil dari kontribusi motor educability terhadap senam ritmik nomor simpai menggunakan statistic parametric menu Correlate, sub menu Bivariate dan uji regresi.

\section{HASIL}

\section{Hasil Data Deskriptif}

Deskriptif hasil data motor educability dan senam ritmik siswa SD Negeri se-Kota Makassar yang diperoleh tersebut dapat dilihat pada tabel 5 berikut:

Tabel 5. Hasil Analisis Deskripsi Data Motor educability dan Kemampuan Senam Ritmik

\begin{tabular}{lccccccc}
\hline \multicolumn{1}{c}{ Nilai statistik } & $\mathbf{n}$ & Mean & S & Range & Min & Max & Sum \\
\hline Motor educability & 140 & 35,0286 & 3,88678 & 20,00 & 24,00 & 44,00 & 4904,00 \\
\hline Senam ritmik & 140 & 3,3342 & 0,55734 & 2,60 & 2,10 & 4,70 & 466,79
\end{tabular}




\section{Persentasi Frekuensi Klasifikasi Motor Educability Senam Ritmik}

Gambaran persentasi frekuensi data penelitian secara keseluruhan dari hasil motor educability senam ritmik pada siswa SD Negeri se-Kota Makassar dapat dilihat pada tabel 6.

Tabel 6. Persentasi frekuensi hasil data motor educability senam ritmik

\begin{tabular}{rcccc}
\hline Nilai & Frekuensi & Persen (\%) & Klasifikasi & Keterangan \\
\hline $60-65$ & 0 & 0,0 & Sangat Baik & 4 \\
$50-59$ & 0 & 0,0 & Baik & 3 \\
$30-49$ & 133 & 95,0 & Cukup & 2 \\
$<30$ & 7 & 5,0 & Kurang & 1 \\
\hline Jumlah & 140 & 100 & & \\
\hline
\end{tabular}

Hasil penelitian ini dapat juga diinterpretasikan dalam bentuk grafik lingkaran pada gambar 1 berikut:

\section{Frekuensi Sebaran Motor Educability}

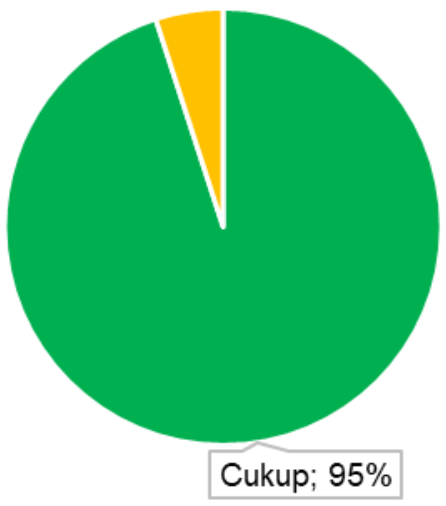

- Sangat Baik - Baik - Cukup " Kurang

Gambar 1. Grafik persentasi hasil data motor educability senam ritmik

Berdasarkan hasil penelitian motor educability senam ritmik secara keseluruhan dari beberapa item tes pada siswa SD Negeri se-Kota Makassar, diketahui bahwa dari 140 sampel siswa ternyata yang memiliki klasifikasikan cukup sebanyak 133 orang $(95,0 \%)$ dan klasifikasi kurang sebanyak 7 orang $(5,0 \%)$, serta tidak ada siswa yang memiliki klasifikasi baik sekali dan baik. Dengan demikian, dapat disimpulkan bahwa hasil 
penelitian data motor educability senam ritmik pada siswa SD Negeri seKota Makassar dikategorikan cukup.

\section{Hasil Pengujian Analisis Data Regresi antara Motor educability Terhadap Kemampuan Senam Ritmik}

Analisis regresi dilakukan untuk mengetahui hubungan, kontribusi dan pengaruh antara variabel bebas dengan variabel terikat pada taraf signifikan $95 \%$ atau $\alpha 0,05$. Hasil-hasil analisis regresi secara lengkap dapat dilihat pada rangkuman hasil analisis tercantum pada tabel 7 berikut:

Tabel 7. Rangkuman Hasil Analisis Korelasi dan Regresi

\begin{tabular}{lcccccc}
\hline \multicolumn{1}{c}{ Hipotesis } & $\mathbf{N}$ & $\mathbf{r} / \mathbf{R}$ & $\mathbf{R s}$ & $\mathbf{F}$ & $\mathbf{t}$ & Sig.t \\
\hline $\begin{array}{l}\text { Kontribusi motor educability } \\
\text { terhadap kemampuan senam ritmik } \\
\text { pada siswa }\end{array}$ & 140 & 0,222 & 0,049 & 7,128 & 2,670 & 0,008 \\
\hline
\end{tabular}

Dari tabel 7 dapat ditarik suatu kesimpulan bahwa pengujian analisis korelasi dan regresi data motor educability terhadap kemampuan senam ritmik pada siswa SD se-Kota Makassar pada tabel 7 diperoleh nilai regresi (Ro) 0,222 dengan tingkat probabilitas $(0,000)<\alpha 0,05$, untuk nilai $\mathrm{R}$ Square (koefesien determinasi) 0,049. Hal ini berarti 4,9\% kemampuan senam ritmik dijelaskan oleh motor educability. Sedangkan sisanya (100\% - 4,9\% = 95,1\%) dijelaskan oleh sebab-sebab yang lain. Dari uji Anova atau $\mathrm{F}$ test, didapat $\mathrm{F}$ hitung adalah 7,128 dengan tingkat signifikansi 0,000 . Oleh karena probabilitas $(0,000)$ jauh lebih kecil dari $\alpha 0,05$, maka model regresi dapat digunakan untuk memprediksi kemampuan senam ritmik (dapat diberlakukan untuk populasi dimana sampel diambil). Sedangkan untuk uji t untuk menguji signifikansi konstanta dan variabel dependen (kemampuan senam ritmik). Nilai thitung diperoleh 2,670 pada kolom Sig/significance adalah 0,008, atau probabilitas jauh di bawah $\alpha$ 0,05. Maka $\mathrm{Ho}_{\mathrm{o}}$ ditolak dan $\mathrm{H}_{1}$ diterima atau koefesien korelasi dan regresi signifikan, atau motor educability benar-benar berpengaruh secara signifikan terhadap kemampuan senam ritmik. Dengan demikian ada kontribusi motor educability terhadap kemampuan senam ritmik pada siswa SD se-Kota Makassar sebesar 4,9\%. 


\section{PEMBAHASAN}

Ada pengaruh motor educability terhadap kemampuan senam ritmik pada siswa SD se-Kota Makassar sebesar 4,9\%. Ada kontribusi motor educability terhadap kemampuan senam ritmik pada siswa SD se-Kota Makassar sebesar 4,9\%. Dari hasil penelitian yang diperoleh ini menunjukkan bahwa kontribusi motor educability terhadap kemampuan senam ritmik pada siswa SD Negeri se-Kota Makassar dikategorikan sangat rendah. Motor educability merupakan dasar dalam gerak setiap individu dalam aktivitas keseharian (Saputra, 2019), akan tetapi dalam pengembangan kemampuan atau keterampilan suatu cabang olahraga adalah dasar untuk menjadi sebuah gerak yang terarah (Wiradihardja, 2017), Penelitian Kashyap, Rajpal, \& Chat (2019) mengungkapkan bahwa motor educability dapat mempengaruhi kemampuan belajar karena motor educability berhubungan dengan kemampuan berfikir dalam melakukan keterampilan. Selain itu penelitian dari Karkare (2015) mengungkapkan bahwa motor educability yang buruk dapat mempengaruhi keterampilan fisik. Selain itu menurut Sujana, Muhtar, \& Nuryadi (2014) mengungkapkan kualitas potensial motor educability akan memberikan gambaran mengenai kemampuan seseorang dalam mempelajari gerakangerakan yang baru dengan mudah. Jika anak usia dini memiliki motor educability yang baik maka sangat membantu anak untuk membuat keputusan secara cepat dan cermat dalam suatu tugas pada hal ini adalah kegiatan olahraga atau senam ritmik.

Senam ritmik merupakan olahraga yang menuntut kemampuan koordinasi untuk melakukan berbagai gerakan alat (Dwi Pradipta, 2017). Koordinasi yang baik mendukung ketrampilan kemampuan motorik (Andriani, Purwanto, \& Adriani, 2019), ketepatan musik dengan berbagai ketentuan peraturan pada code of point (COP). Kemampuan motorik meliputi koordinasi, keseimbangan dinamis, keseimbangan statis, pendalaman rasa/ ekpsresi, waktu pergerakan, kecepatan, reaksi dan antisipasi tubuh (Ahmed, 2016). Selain itu disebutkan juga pada senam ritmik ada beberapa unsur gerak yang harus dikuasai yaitu balance, 
rotation, jumping, keterampilan penguasaan alat dalam melempar dan menangkap alat, serta penguasaan ekspresi terhadap gerakan, alat dan musik (Islamia \& Marhaendra, 2019), sehingga mekanisme peran motor educability terhadap kemampuan senam ritmik berhubungan dengan cepat tidaknya seorang siswa sekolah dasar dalam mempelajari sebuah unsur gerakan pada senam ritmik.

Seorang peserta didik akan memiliki kemampuan motor educability yang baik apabila rajin serta aktif dalam berlatih, sehingga nantinya kemampuan tersebut akan memberikan kontribusi kepada individu agar mampu mempelajari secara cepat dan cermat kecakapan dasar dan keterampilan motorik (Lesmana, 2018). Hasil penelitian lain menyebutkan bahwa motor educability akan meningkat dengan bertambahnya usia (Kashyap, 2017). Dalam belajar gerak, tingkat motor educability berpengaruh terhadap kemampuan siswa menerima keterampilan teknik dasar serta mempengaruhi keterampilan bermain pada cabang olahraga (Hamidi, 2019). Hasil penelitian ini menunjukkan bahwa siswa Sekolah Dasar Negeri yang ada di Kota Makassar memiliki kemampuan motor educability yang masuk kategori cukup, sehinga hasil penelitian Ini membuktikan bahwa dengan kemampuan motor educability yang cukup akan memiliki dapak yang rendah yakni sebesar 4,9\% terhadap keharmonisan gerak senam ritmik yang dilakukan siswa Sekolah Dasar sedangkan 95,1\% di pengaruhi faktor lain yang perlu diteliti lebih lanjut.

Berdasarkan rendahnya motor educability yang didapatkan pada siswa SD Negeri se-Kota Makassar, dikarenakan sebab rata-rata siswa belum mampu merangkai gerakan yang sebenarnya pada senam ritmik pada alat simpai. Ini disebabkan pengajaran di sekolah cabang olahraga senam khususnya ritmik tidak di ajarkan dalam bentuk merangkai sebuah gerakan, akan tetapi lebih mengarah pada teknik-teknik dasar dalam melakukan gerakan pada alat simpai. Di lain sisi, gerakan senam ritmik pada alat simpai atau hoop ini hanya dilakukan sekali atau tidak difokuskan hingga akhir dalam sebuah rangkaian gerak yang sebenarnya dengan menggunakan musik yang sesuai saat diperlombakan atau 
dipertandingkan. Sekolah hanya dijadikan wadah dalam proses pembelajaran kepada siswa untuk dapat memahami dan mengetahui teknik-teknik dasar pada sebuah cabang olahraga seperti senam ritmik. Sedangkan untuk tindak lanjut dalam mengembangkan kemampuan setiap individu khususnya senam ritmik pada alat simpai perlu meluangkan waktu untuk masuk pada club-club senam usia dini. Pada penelitian ini masih memiliki keterbatasan yakni pada alat yang digunakan dalam penelitian ini yakni simpai, diharapkan dapat memanfaatkan alatalat yang lain yang dapat digunakan karena masih banyak alat-alat yang dapat digunakan yang mempengaruhi motor educability dalam senam ritmik.

\section{KESIMPULAN}

Hasil studi menunjukkan bahwa motor educability memiliki kontribusi terhadap kemampuan senam ritmik pada siswa SD se-Kota Makassar sebesar 4,9\%. Melalui hasil ini diharapkan guru olahraga agar dapat mengetahui dan memahami tentang perkembangan dan pertumbuhan motorik anak didik agar dapat diarahkan pada kemampuan gerak yang lebih baik untuk setiap cabang olahraga khususnya pada senam ritmik. Peneliti menyadari bahwa hasil penelitian ini dapat dijadkan suatu pijakan dalam memahami pentingnya motor educability pada siswa didik. Jadi kedepannya perlu adanya peningkatan bagi peneliti selanjutnya terkait motor educability dengan senam ritmik denagn alat selain simpai, agar memperoleh hasil penelitian yang lebih baik dan dapat mengembangkan prestasi olahraga khususnya cabang olahraga senam secara maksimal.

\section{REFERENSI}

Adji, W. S. (2017). Penanaman Nilai Sosial Anak Usia Dini Melalui Gerak dan Lagu. JEA (Jurnal Edukasi AUD), 2(2), 110-117. https://doi.org/10.18592/jea.v2i2.1545

Ahmed, R. H. (2016). Impact of Coordination Abilities Program On Accuracy and Speed in Rhythmic Gymnastics. Ovidius University Annals, Series Physical Education \& Sport/Science, Movement \& Health, 16(2). 
Akbari, M. (2014). Hubungan Motor educability, Indeks Massa Tubuh dan Motivasi Belajar dengan Prestasi Belajar Penjasorkes. Jurnal Sport Pedagogy: Program Pascasarjana Unsyiah, 4(1).

Andriani, R., Purwanto, B., \& Adriani, M. (2019). Uji Psikomotor Waktu Reaksi Pada Siswa Yang Sarapan Dan Tidak Sarapan. Amerta Nutrition, 3(1), 7-12. https://doi.org/10.20473/amnt.v3i1.2019.7-12

Aryamanesh, S., \& Sayyah, M. (2014). Effect of some selected games on the develop-ment of locomotor skills in 4-6 year-old preschool boys. International Journal of Sport Studies, 4(6), 648-652.

Atiyah, R. I., Wahidin, W., \& Roviati, E. (2016). Penggunaan lembar kerja siswa (LKS) berbasis Keterampilan Proses Sains (KPS) untuk meningkatkan literasi sains siswa pada konsep kingdom plantae Kelas X Di Sman 3 Kuningan. Scientiae Educatia: Jurnal Pendidikan Sains, 5(2), 144-155.

Aulia, F. (2015). Aplikasi Psikologi Positif dalam Konteks Sekolah. Seminar Psikologi Dan Kemanusiaan.

Azizah, N. N., \& Richval, A. A. (2018). Pertumbuhan dan Perkembangan Dalam Psikologi Perkembangan. Jurnal Psikologi Perkembangan, 1-13.

Baharun, H. (2016). Pendidikan Anak dalam Keluarga; Telaah Epistemologis. Jurnal Pedidikan, 3(2).

Bardid, F., Lenoir, M., Huyben, F., De Martelaer, K., Seghers, J., Goodway, J. D., \& Deconinck, F. J. (2017). The effectiveness of a community-based fundamental motor skill intervention in children aged 3-8 years: Results of the "Multimove for Kids" project. Journal of Science and Medicine in Sport, 20(2), 184-189.

Basri, B. (2019). Meningkatkan Perkembangan Motorik melalui Senam Ritmik pada Siswa Kelas VI Sekolah Dasar. Jurnal Pendidikan: Teori, Penelitian, dan Pengembangan, 4(3), 387-392.

Cahyono, H. (2016). Pola pengembangan pendidikan karakter siswa (Sebuah studi di SDN 1 Polorejo). Jurnal Dimensi Pendidikan dan Pembelajaran, 3(2), 5-12.

Di Cagno, A., Fiorilli, G., Iuliano, E., Tsopani, D., Buonsenso, A., Piazza, M., \& Calcagno, G. (2018). Disordered eating behaviors in rhythmic gymnasts: a survey to investigate the coaches' point of view on the management. Journal of Physical Education and Sport, 18(3), 1748-1755. https://doi.org/10.7752/jpes.2018.03254

Dwi Pradipta, G. (2017). Strategi Peningkatan Keterampilan Gerak Untuk Anak Usia Dini Taman Kanak-Kanak B. Jendela Olahraga, 2(1). https://doi.org/10.26877/jo.v2i1.1292

Fernández-Villarino, M. A., Hernaiz-Sánchez, A., Sierra-Palmeiro, E., \& Bobo-Arce, M. (2018). Performance indicators in individual rhythmic gymnastics: Correlations in competition. Journal of 
Human Sport and Exercise, 13(3), 487-493. https://doi.org/10.14198/jhse.2018.133.01

Gymnastique, F. I. d. (2009). Code Of Points Rhythmic Gymnastics 2009 2012. France: Printed FIG.

Hamidi, A. (2019). The Influences Of Learning Model And Motor educability In Technical Learning Results And Basketball Playing Skills For Junior High School Students Sport Science Study Program. UPI: Bandung.

Hanief, Y. N., \& Sugito, S. (2015). Membentuk gerak dasar pada siswa sekolah dasar melalui permainan tradisional. Jurnal SPORTIF: Jurnal Penelitian Pembelajaran, 1(1), 100-113. https://doi.org/10.29407/js_unpgri.v1i1.575

Haqiyah, A., \& Riyadi, D. N. (2018). Pengaruh Inteligensi, Kelentukan, dan Motor Educability terhadap Hasil Belajar Jurus Tunggal Pencak Silat. Perspektif Ilmu Pendidikan, 32(1), 7-13.

Herlambang, T. (2017). Aerobic Gymnastics Sebagai Pembelajaran Aktivitas Ritmik Pada Pendidikan Jasmani Olahraga Dan Kesehatan. Jendela Olahraga, 2(1), 92-89. https://doi.org/10.26877/jo.v2i1.1286

Houwen, S., Visser, L., van der Putten, A., \& Vlaskamp, C. (2016). The interrelationships between motor, cognitive, and language development in children with and without intellectual and developmental disabilities. Research in Developmental Disabilities, 53, 19-31.

Hughes, F. P. (2009). Children, play, and development: Sage.

Islamia, A., \& Januarumi Marhaendra, F. (2019). Analisis Skor Gerak Rangkaian Senam Ritmik Pada Alat Pita. Jurnal Prestasi Olahraga, 2(3).

Juntara, P. E. (2019). Latihan Kekuatan Dengan Beban Bebas Metode Circuit Training Dan Plyometric. Altius: Jurnal IImu Olahraga Dan Kesehatan, 8(2). https://doi.org/10.36706/altius.v8i2.8705

Karkare, A. Y. (2015). Effect of motor educability and tribal and non tribal belongingness on physical skills of male players. Res $J$ Recent Sci, 4, 162-164.

Kashyap, N. N. (2017). A study on progression of motor educability in boys from pre-adolescence to adolescence. International Journal of Yogic, Human Movements and Sports Sciences, 2(1), 43-44.

Kemendikbud. (2004). Instrumen Pemanduan Bakat SENAM. Jakarta: Drektorat Jendral Olahraga.

Lavin, J. (2008). Creattive approaches to physical education: helping children to achieve their true potential. New York: Routledge. 
Lesmana, H. S. (2018). Peran Motor Educability di dalam Meningkatkan Keterampilan Olahraga pada Pembelajaran Penjas. Halaman Olahraga Nusantara: Jurnal IImu Keolahragaan, 1(1), 115-125.

Mahardhika, D. B. (2016). Pengaruh Metode Pembelajaran Latihan dan Motor educability Terhadap Keterampilan Dribel Bola Basket. Judika (Jurnal Pendidikan Unsika), 4(2).

Makulua, K. (2018). Strategi Guru Dalam Meningkatkankreativitas Anak Usia Taman Kanak-Kanak. KENOSIS: Jurnal Kajian Teologi, 1(1), 89-107. https://doi.org/10.37196/kenosis.v1i1.23

Mahardhika, D. B. (2016). Pengaruh Metode Pembelajaran Latihan dan Motor educability Terhadap Keterampilan Dribel Bola Basket. Judika (Jurnal Pendidikan Unsika), 4(2).

Masykuri, M., \& Saputro, S. (2015). Pengembangan Multimedia Simulatif Kimia Berbasis Inkuiri Terbimbing Pada Materi Analisis Kualitatif Kation Golongan 1. INKUIRI: Jurnal Pendidikan IPA, 4(3), 120126.

Miletić, D., Katić, R., \& Males, B. (2004). Some anthropologic factors of performance in rhythmic gymnastics novices. Collegium antropologicum, 28(2), 727-737.

Murwaningsih, D. (2018). Upaya Meningkatkan Hasil Belajar Matematika melalui Pembelajaran Kooperatif dengan Pendekatan Struktur Siswa Kelas V SDN 3 Singotrunan Kec. Banyuwangi Kab. Banyuwangi Tahun Ajaran 2016-2017. ELSE (Elementary School Education Journal): Jurnal Pendidikan dan Pembelajaran Sekolah Dasar, 2(2), 102-113. https://doi.org/10.30651/else.v2i2.1831

Nugraha, J., Zulela, M. S., \& Fuad, N. (2019, February). Peningkatan Keterampilan Menulis Deskripsi Melalui Pendekatan Saintifik Dengan Metode Problem Based Learning Di Kelas IV Sekolah Dasar. In Prosiding Seminar Nasional Pendidikan KALUNI (Vol. 2).

Primasoni, N. (2012). Manfaat Protein untuk Mendukung Aktivitas Olahraga, Pertumbuhan, dan Perkembangan Anak Usia Dini. Universitas Negeri Yogyakarta: Fakultas Ilmu Olahraga.

Rahmadani, N. K. A. (2014). Peningkatan Keterampilan Motorik Kasar Melalui Permainan Tradisional Jawa. Jurnal Pendidikan Usia Dini, 8(2), 315-324.

Ristanti, D. I., Setiawan, W., \& Setiawan, D. (2019). Pengaruh Pembelajaran Menggunakan Media Hullahop Terhadap Peningkatan Hasil Belajar Senam Lantai Pada Siswa Kelas VIII Di SMP Negeri 1 Pakusari. Jurnal Kejaora (Kesehatan Jasmani Dan Olah Raga), 4(1), 16-20. https://doi.org/10.36526/kejaora.v4i1.617

Sari, H. E., \& Karmila, M. (2015). Upaya Meningkatkan Kemampuan Motorik Kasar Melalui Permainan Simpai Pada Kelompok B Di Kb- 
TK Islam Permata 1 Semarang. PAUDIA: Jurnal Penelitian dalam Bidang Pendidikan Anak Usia Dini, 4(1).

Sari, R. M., Valentin, R. G., \& Samosir, A. (2017). Upaya Meningkatkan Konsentrasi Melalui Latihan Relaksasi Atlet Senam Ritmik Sumut. Sains Olahraga: Jurnal IImiah IImu Keolahragaan, 1(1), 52-63. https://doi.org/10.24114/so.v1i1.6132

Setiawan, I. (2018). Profil tingkat kondisi fisik atlet tarung derajat Kota Kediri dalam mempersiapkan kejuaraan Porprov tahun 2018. Briliant: Jurnal Riset dan Konseptual, 3(4), 475-484. https://doi.org/10.28926/briliant.v3i4.251

Setyawan, D. A., Hadi, H., \& Royana, I. F. (2018). Kemampuan Motorik Kasar Anak Usia 5-6 Tahun di TK Negeri Pembina Kota Surakarta. Jurnal Penjakora, 5(1), 17-27.

Saputra, A. S. D. (2019). Korelasi Antara Motor Ability Dengan Keterampilan Dasar Bermain Bola Voli Pada Siswa Berusia 18-19. Jurnal Maenpo, 9(1), 30-36. https://doi.org/10.35194/jm.v9i1.906

Sujana, R., Muhtar, T., \& Nuryadi, N. (2014). Pengaruh Pendekatan Pembelajaran dan Motor Educability Terhadap Hasil Belajar Teknik Dasar dan Keterampilan Bermain Sepakbola. Edusentris, 1(3), 260-274.

Sujiono, B., Sumantri, M. S., \& Chandrawati, T. (2010). Hakikat Perkembangan Motorik Anak. Modul PGTK, Universitas Terbuka.

Utami, D. S., Kartika, A. E., Damayanti, A., \& Nugroho, S. (2004). Senam Ritmik untuk Meningkatkan Konsentrasi Belajar pada Anak. Psikologika: Jurnal Pemikiran dan Penelitian Psikologi, 9(18), 4553. https://doi.org/10.20885/psikologika.vol9.iss18.art5

Wiradihardja, S. (2017). Pengembangan Model Latihan Gerak Multilateral Cabang Olahraga Renang. JURNAL PENJAKORA, 3(1), 49-65.

Zaman, B., Hernawan, A., \& Eliyawati, C. (2005). Media dan Sumber Belajar TK. Modul Universitas Terbuka: Jakarta: Pusat Penerbitan Universitas Terbuka. 